\title{
Research on Accurate Information Pushing Based on Human Network
}

\author{
Meijie Yang, Yu Wang, Xiaorong Hou* \\ College of Medical Informatics, Chongqing Medical University, Chongqing, China \\ Email: ymeijie@sina.cn, 1042334219@qq.com, ${ }^{*}$ hxrhelen@163.com
}

How to cite this paper: Yang, M.J., Wang, Y. and Hou, X.R. (2017) Research on Accurate Information Pushing Based on $\mathrm{Hu}$ man Network. Social Networking, 6, 181196.

https://doi.org/10.4236/sn.2017.62011

Received: January 26, 2017

Accepted: April 27, 2017

Published: April 30, 2017

Copyright $\odot 2017$ by authors and Scientific Research Publishing Inc. This work is licensed under the Creative Commons Attribution International License (CC BY 4.0).

http://creativecommons.org/licenses/by/4.0/

(c) (i) Open Access

\begin{abstract}
Based on the social network analysis methods and human network, this paper randomly selected 44 students ( 31 males and 13 females) as the research objects, and it used the UCINET software to analyze the friendship between them of which 43 used WeChat and 44 used QQ, and it also used the tool Netdraw to visualize the network sociogram. By mining the four aspects of density, accessibility, centrality, block model, the results demonstrated that QQ social network and WeChat social network existed the phenomenon of small world, leaders and subgroups, and the key nodes of QQ human network were more than WeChat network. Through using the key nodes, it can push the precise and efficient information and improve the accuracy of information transmission and impact among network members.
\end{abstract}

\section{Keywords}

Social Network Analysis, Human Network, Small World, Subgroup, Key Nodes: Precise and Efficient Information, Information Transmission

\section{Introduction}

With the development of Web 2.0 and the increasement of using self-media, people can obtain the accurate and effective information by excavating the characteristics and phenomena of social network. Many definitions of the human network have been developed. The social systems which we live with (families, schools, friendship groups, and so on) can be described as networks and analyzed using social network analysis [1]. Some scholars defined it as a relatively stable system composing with some individuals [2]. Some defined it as the social network, which was used by exchanging information to achieve a specific purpose [3]. Others defined it as a relatively stable dynamic system, which was formed by the network of information for a specific purpose [4]. In this paper, the social network is defined as the relatively stable whole network, which is formed by 
certain individuals and the purpose is for formation communication and propagation.

At present, the research of social network mainly focuses on the enterprise competitive intelligence. Bao [3] thought the social network was a social capital of competitive intelligence and enterprise development. It created a new direction in researching the enterprise competitive intelligence of domestic social network. Pan [2] constructed the competitive intelligent human network research model from the quantitative and qualitative aspects, but he didn't analyze the basic characteristics of human network structure. Wang [4] introduced the relational theory of database and constructed the competitive intelligent human network relational model. $\mathrm{Wu}$ [5] used the network links to build virtual social relations. Rachel Isba [6] used social network analysis in medical education; it yielded significant insights that would improve experiences and outcomes for medical educators, and ultimately for patients. Andrea Fronzetti Colladon proposed a new approach to sort and map relational data and used social network metrics to find risk profiles of clients and potential criminals [7]. Wai Kin Victor Chan analyzed how hyper-network models led to the new understanding for service science. And they revealed hidden social structures and yielded accurate estimates for network performance. Finally they proved that hyper-networks enhanced ordinary random graphs [8]. The above studies have not further analyzed the network characteristics.

This paper randomly selects 44 students of certain specialty, and constructs friends adjacency matrix by EXCEL based on the relationship of QQ and WeChat. It uses Ucinet to analyze the social network and Netdraw to visualize the human network sociogram. By computing the Network density, reachability, centrality and block model, it can obtain the small world phenomena of the network, few key nodes and subgroups (small groups) with highest nodes degree dominating the whole network. Through analyzing the key nodes and the information concerned by small groups, it can improve the efficiency of information pushing and avoid the phenomenon of information overloading.

\section{Methods}

\subsection{Research Objects}

This study randomly selected 44 students ( 31 males and 13 females) as the research objects, and it investigated the friendship between them of which 43 used WeChat and 44 used QQ.

\subsection{Related Theories and Research Tools}

The social network refers to the network with complex connection relations, which formed by the social individual as nodes and the relations between the individuals as edges [9]. Social network analysis can be divided into two basic types according to the research groups: Ego-centered network analysis and whole network analysis [10]. The whole network is a comprehensive structure of role relationships in a social system [11]. 
The basic elements of human network include persons and the links between persons. The former can be called nodes and the latter can be called relations or ties [3]. The various phenomena of social network achieved by the social network analysis and software can improve the efficiency of human network and push the targeted precision information.

Ucinet (University of California at Irvine Network) is a comprehensive social network analysis software developed by University of Cingifornia Irvine [12]. The Netdraw of Ucinet can statistical and visual analysis 1D and 2D data [13]. Ucinet can separately process data matrix and convert data matrix to visual network map. It supports a large number of algorithms and can make accurate calculation and analysis for matrix. It can be more competent for pure data computing and more suitable for complex multi-relationship data processing [12].

In this paper, the analysis of social network uses the Ucinet 6.232 version to build two-dimensional adjacency matrix and process network data. The network sociogram is built by the NetDraw 2.118 version.

\section{Network Construction and Network Analysis}

\subsection{Network Construction}

In order to facilitate recording, this paper used numerical number instead of student's name. The relationship between the participants of the study forms a $44 \times$ 44 two-dimensional adjacency matrix. If they are friends of each other, the corresponding element value is 1 and otherwise is 0 . The results are shown in Table 1 and Table 2 as below.

Table 1. Part of friendship matrix of QQ.

\begin{tabular}{cccccccc}
\hline & 01 & 02 & 03 & 04 & $\cdots$ & 43 & 44 \\
\hline 01 & 0 & 1 & 1 & 1 & $\cdots$ & 1 & 1 \\
02 & 1 & 0 & 1 & 1 & $\cdots$ & 1 & 1 \\
03 & 1 & 1 & 0 & 1 & $\cdots$ & 1 & 1 \\
04 & 1 & 1 & 1 & 0 & $\cdots$ & 0 & 1 \\
$\ldots$ & $\ldots$ & $\ldots$ & $\ldots$ & $\ldots$ & $\ldots$ & $\ldots$ & $\cdots$ \\
43 & 1 & 1 & 1 & 0 & $\cdots$ & 0 & 1 \\
44 & 1 & 1 & 1 & 1 & $\cdots$ & 1 & 0
\end{tabular}

Table 2. Part of friendship matrix of WeChat.

\begin{tabular}{cccccccc}
\hline & 01 & 02 & 03 & 04 & $\cdots$ & 43 & 44 \\
\hline 01 & 0 & 1 & 1 & 1 & $\cdots$ & 1 & 0 \\
02 & 1 & 0 & 1 & 1 & $\cdots$ & 1 & 1 \\
03 & 1 & 1 & 0 & 1 & $\cdots$ & 0 & 1 \\
04 & 1 & 1 & 1 & 0 & $\cdots$ & 0 & 1 \\
$\ldots$ & $\ldots$ & $\ldots$ & $\ldots$ & $\ldots$ & $\ldots$ & $\cdots$ & $\cdots$ \\
43 & 1 & 1 & 0 & 0 & $\cdots$ & 0 & 1 \\
44 & 0 & 1 & 1 & 1 & $\cdots$ & 1 & 0 \\
\hline
\end{tabular}




\subsection{The Whole Human Network Analysis}

\subsubsection{Human Network Sociogram}

Netdraw can draw the human network sociogram of QQ and WeChat between students (shown as Figure 1 and Figure 2), and on the basis of it a central visual analysis can be proceeded (shown as Figure 3 and Figure 4).

This paper constructed the undirected and unweighted network. As shown in Figure 1 and Figure 2, each node represents a student and participants of the

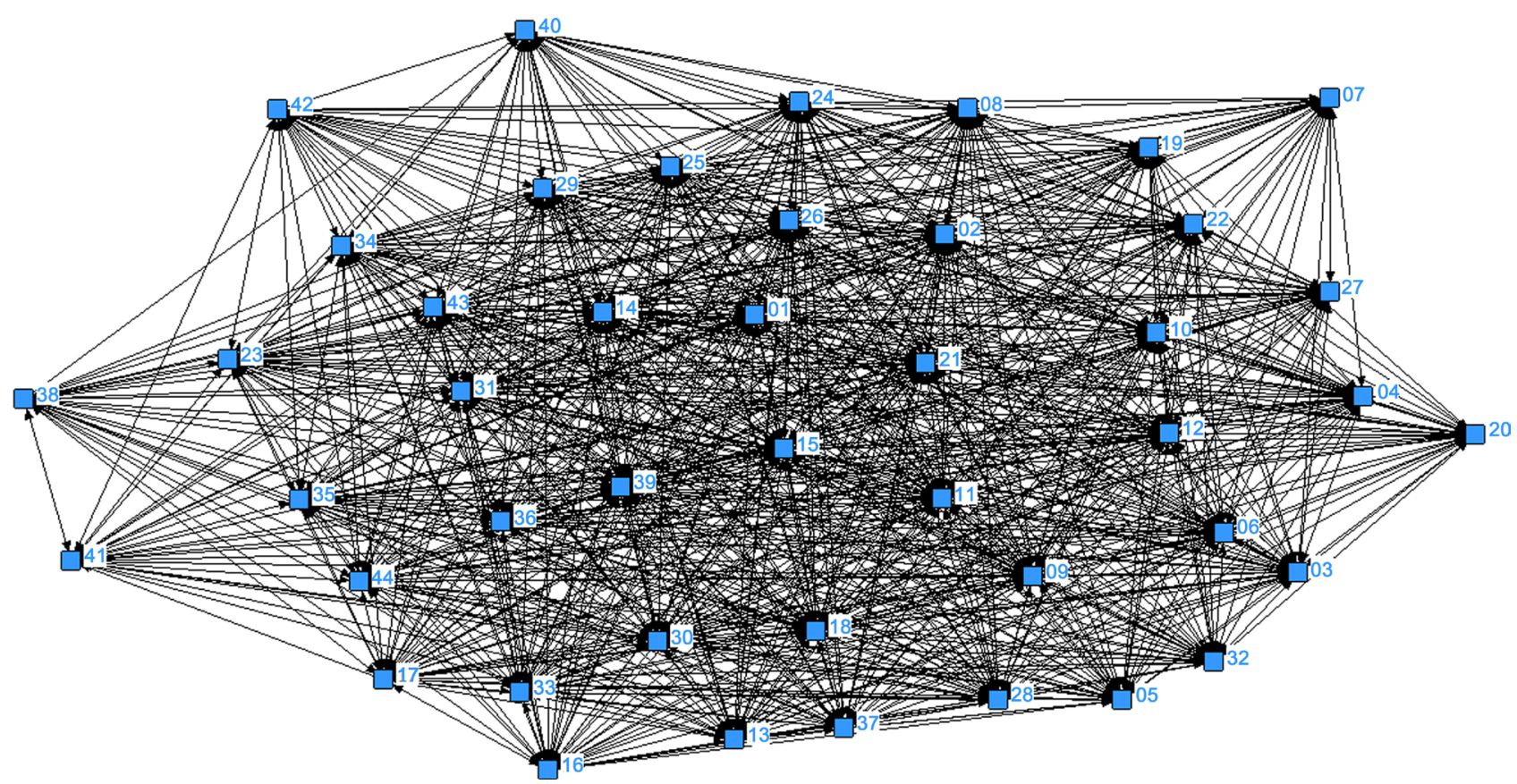

Figure 1. Human network sociogram of QQ.

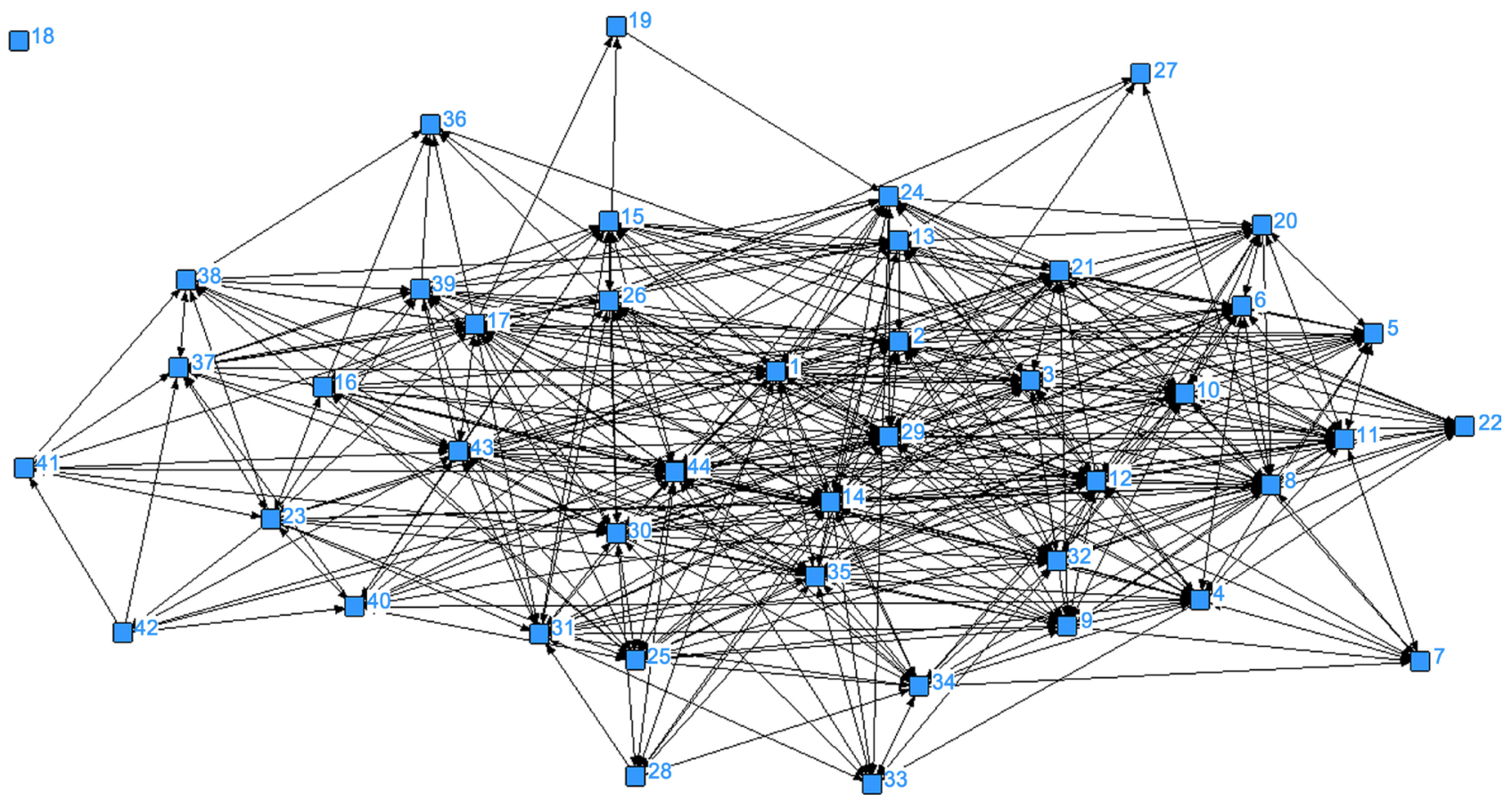

Figure 2. Human network sociogram of WeChat. 


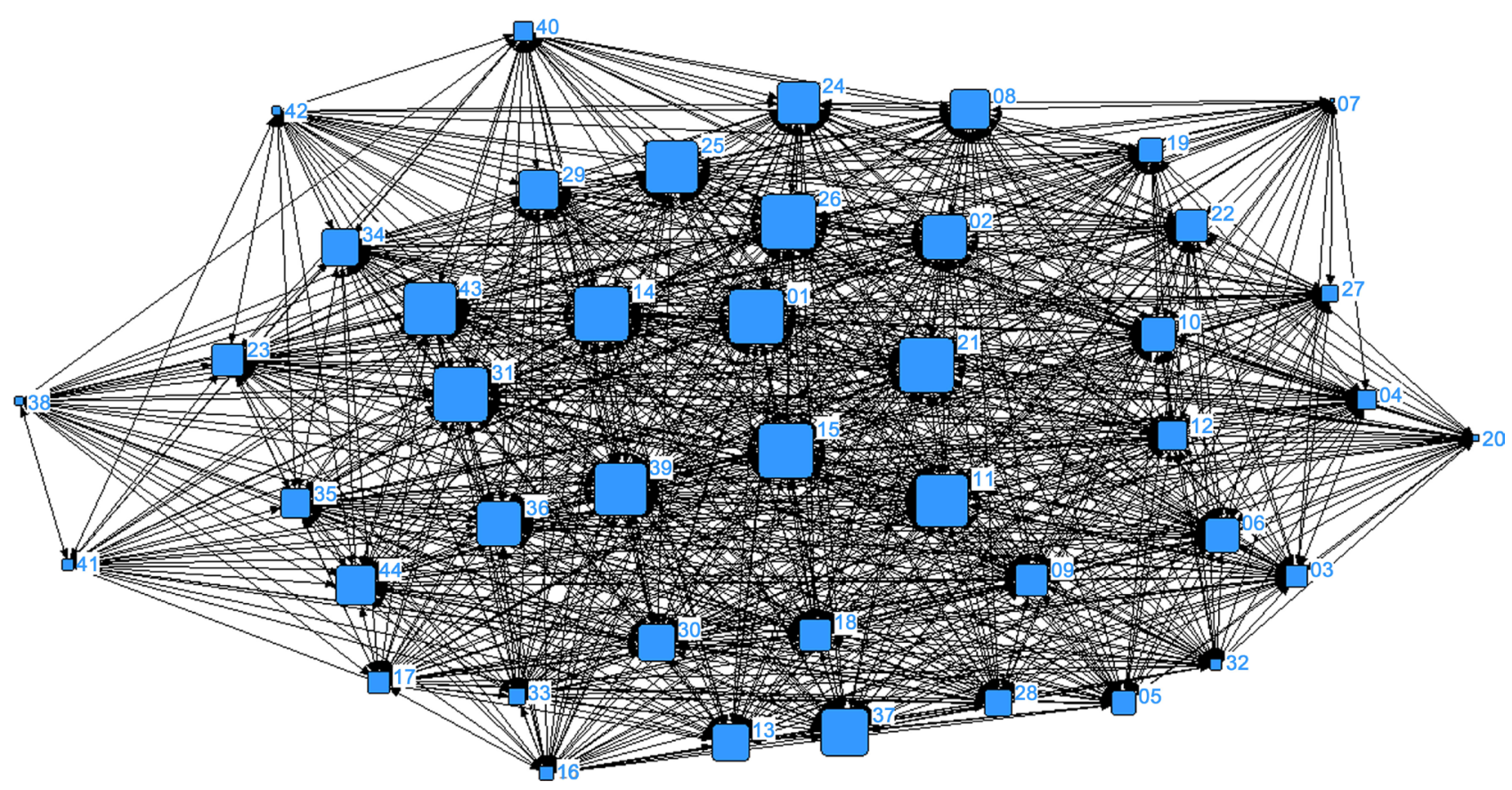

Figure 3. Central visual analysis sociogram of QQ.

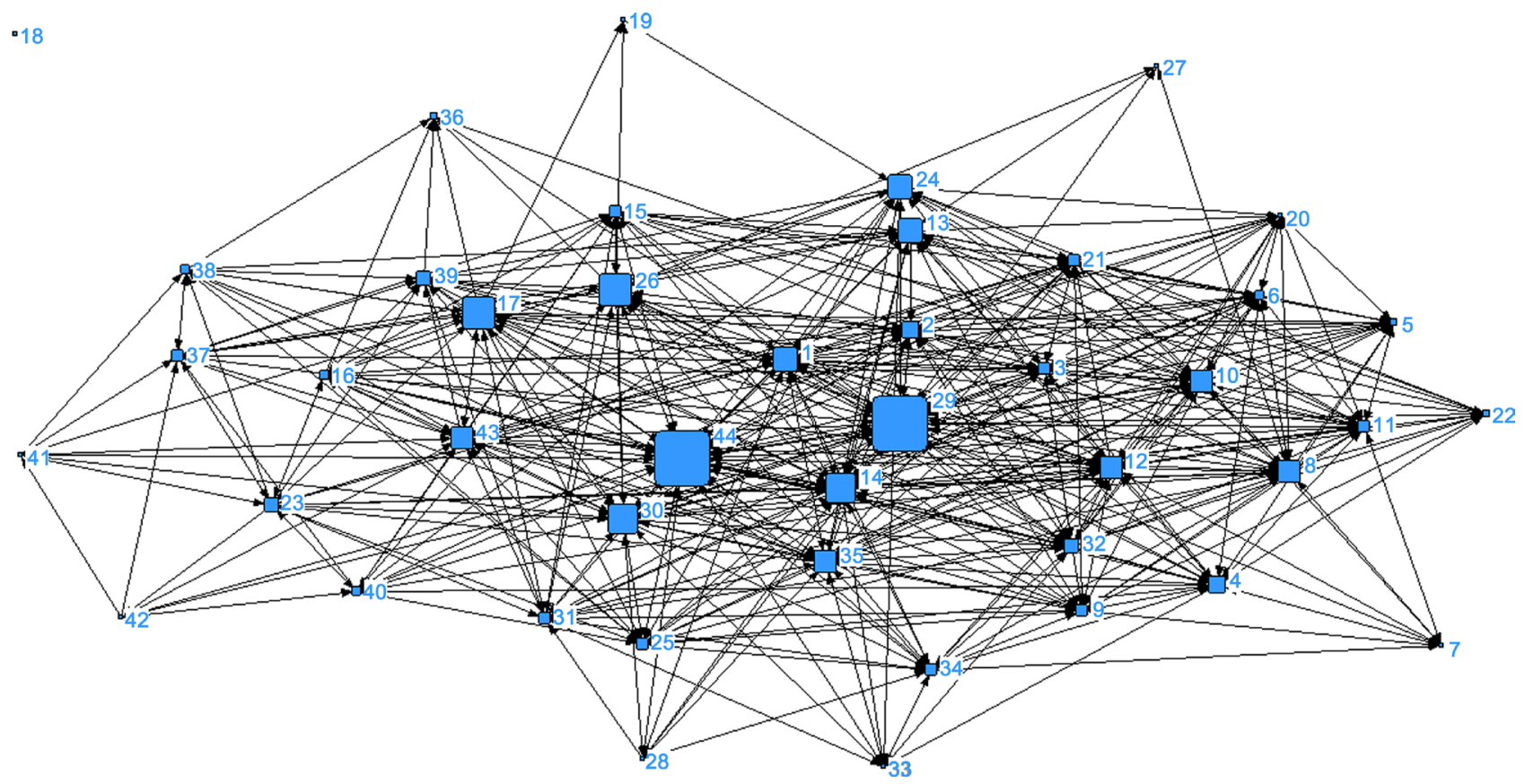

Figure 4. Central visual analysis sociogram of Wechat.

study constitute a node set. If every two students are friends of each other, there is a link that represents their relations. The node 18 of Figure 2 is an acnode because it doesn't use WeChat. The nodes 1, 21, 15, 14 of Figure 3 are the intermediary nodes of human network (that is the nodes in the middle of the human network), The nodes 44, 29 of Figure 4 are the intermediary nodes.

\subsubsection{Human Network Density}

Network density is the most common social network analysis indicator, which 
reflects the close degree of associations between points [11]. Using the function "network-cohesion-density" in the Ucinet can calculate the network density of QQ and WeChat. The results are shown in Table 3.

In the social network, the greater of the network density, the closer connection of the network members, the higher frequency of interactions between members, and it is more conducive to disseminate and share the knowledge. The greater of the whole network density, the greater the impact on member internal behavior, attitudes, and it can obtain better teamwork. Coleman thought that the higher the degree of interaction between members, which leaded to a more positive impact on the group operation [14].

Table 3 shows that the average of QQ human network density is 0.8578 which is greater than 0.5. It illustrates that the relation among the members is closer, and the communication is more interactive. The compat human network can effectively push and disseminate the accurate information. The average density of WeChat is 0.3552 and the network density is low. It shows that the connection of human network members in WeChat is not close enough and the communication or the interaction is weak. The whole human network has less influence on the inner behaviors and attitudes of members.

\subsubsection{Human Network Accessibility}

The function "network-cohesion-distance" in Ucinet can analyze the network accessibility, which can verify whether the network is a small world or not [15]. The small-world effect has an important significance of researching the convenience among members in human network and the speed of information flow [15]. The results are shown in the following table.

Table 4 shows that the average distance among human network nodes of $\mathrm{QQ}$, which is 1.142 and that of WeChat is 1.652 . The average distances of the two networks are less than 2, which means every two nodes can connect with each other within two students. The fast spreading has a significant small world effect and it also shows that the information exchanging among members of the network quickly and fluently.

Table 4 also shows that cohesiveness index of based on distance of QQ is 0.929 and that of WeChat is 0.639 . The greater cohesion index means the stronger cohesion of members in the network [15]. The higher cohesion indexes of the

Table 3. The human network density of QQ and WeChat.

\begin{tabular}{ccc}
\hline & QQ & WeChat \\
\hline Network Density & 0.8578 & 0.3552 \\
Standard Deviation & 0.3492 & 0.4786 \\
\hline
\end{tabular}

Table 4. The average distance among human network nodes of QQ and WeChat.

\begin{tabular}{ccc}
\hline & QQ & WeChat \\
\hline Average Distance among Nodes & 1.142 & 1.652 \\
Cohesiveness Index & 0.929 & 0.639 \\
\hline
\end{tabular}


two human networks indicate the better cohesion among the human network members, which promote the information dissemination and sharing among human network members, and it also promotes the accurate information pushing in. human network.

\subsection{Human Network Centricity}

Centricity is one of the important contents of social network analysis, and it is an important index of measuring rights or central position. The central position individual of social network has strong influence on others and owns a high social prestige. Degree centrality, closeness centrality and betweenness centrality are the three most common forms to describe the network centricity.

\subsubsection{Degree Centrality}

Degree centrality refers to the number of connections between some node and other nodes in the network [16]. It contains node indegree and node outdegree.

Node indegree is the degree to which one node is concerned by other nodes. Node outdegree is the degree to which one node pays attention to other nodes. The nodes with higher node indegree indicate that they are followed by other

\begin{tabular}{|c|c|c|c|c|}
\hline & $\begin{array}{r}1 \\
\text { OutDegree }\end{array}$ & InDegree & NrmOutDeg & NrmInDeg \\
\hline & 43.000 & 43.000 & 100.000 & 100.000 \\
\hline $\begin{array}{l}202 \\
3\end{array} 03$ & 42.000 & 42.000 & 97.674 & 97.674 \\
\hline 303 & 38.000 & 38.000 & 88.372 & 88.372 \\
\hline 404 & 35.000 & 35.000 & 81.395 & 81.395 \\
\hline 505 & 36.000 & 33.000 & 83.721 & 76.744 \\
\hline $\begin{array}{l}606 \\
7\end{array}$ & 39.000 & 39.000 & 90.698 & 90.698 \\
\hline $\begin{array}{ll}7 & 07 \\
8 & 08\end{array}$ & 25.000 & 25.000 & 58.140 & 58.140 \\
\hline $\begin{array}{ll}8 & 08 \\
9 & 09\end{array}$ & 39.000 & 39.000 & 90.698 & 90.698 \\
\hline $\begin{array}{rl}909 \\
10 & 10\end{array}$ & $\begin{array}{l}40.000 \\
38.000\end{array}$ & $\begin{array}{l}38.000 \\
40.000\end{array}$ & $\begin{array}{l}93.023 \\
88.372\end{array}$ & $\begin{array}{l}88.372 \\
93.023\end{array}$ \\
\hline 1111 & 42.000 & 42.000 & 97.674 & 97.674 \\
\hline 1212 & 37.000 & 39.000 & 86.047 & 90.698 \\
\hline 1313 & 40.000 & 40.000 & 93.023 & 93.023 \\
\hline $14 \quad 14$ & 43.000 & 43.000 & 100.000 & 100.000 \\
\hline 1515 & 43.000 & 43.000 & 100.000 & 100.000 \\
\hline 1616 & 29.000 & 33.000 & 67.442 & 76.744 \\
\hline 1717 & 37.000 & 34.000 & 86.047 & 79.070 \\
\hline 1818 & 40.000 & 40.000 & 93.023 & 93.023 \\
\hline 1919 & 35.000 & 36.000 & 81.395 & 83.721 \\
\hline 2020 & 29.000 & 29.000 & 67.442 & 67.442 \\
\hline $\begin{array}{l}21 \\
22\end{array}$ & 43.000 & 43.000 & 100.000 & 100.000 \\
\hline $\begin{array}{l}2222 \\
2323\end{array}$ & $\begin{array}{l}26.000 \\
37.000\end{array}$ & $\begin{array}{l}37.000 \\
37.000\end{array}$ & $\begin{array}{l}60.465 \\
86.047\end{array}$ & $\begin{array}{l}86.047 \\
86.047\end{array}$ \\
\hline $24 \quad 24$ & 40.000 & 40.000 & 93.023 & 93.023 \\
\hline $25 \quad 25$ & 41.000 & 39.000 & 95.349 & 90.698 \\
\hline 2626 & 43.000 & 43.000 & 100.000 & 100.000 \\
\hline 2727 & 35.000 & 34.000 & 81.395 & 79.070 \\
\hline $28 \quad 28$ & 38.000 & 38.000 & 88.372 & 88.372 \\
\hline 2929 & 41.000 & 39.000 & 95.349 & 90.698 \\
\hline 3030 & 40.000 & 38.000 & 93.023 & 88.372 \\
\hline 3131 & 43.000 & 43.000 & 100.000 & 100.000 \\
\hline 3232 & 36.000 & 36.000 & 83.721 & 83.721 \\
\hline $\begin{array}{ll}33 & 33 \\
34 & 34\end{array}$ & $\begin{array}{l}36.000 \\
27.000\end{array}$ & 36.000 & $\begin{array}{l}83.721 \\
62791\end{array}$ & $\begin{array}{l}83.721 \\
88.372\end{array}$ \\
\hline $\begin{array}{ll}34 & 34 \\
35 & 35\end{array}$ & $\begin{array}{l}27.000 \\
35.000\end{array}$ & $\begin{array}{l}38.000 \\
36.000\end{array}$ & $\begin{array}{l}62.791 \\
81.395\end{array}$ & $\begin{array}{l}88.372 \\
83.721\end{array}$ \\
\hline 3636 & 42.000 & 39.000 & 97.674 & 90.698 \\
\hline $37 \quad 37$ & 40.000 & 36.000 & 93.023 & 83.721 \\
\hline $38 \quad 38$ & 25.000 & 24.000 & 58.140 & 55.814 \\
\hline 3939 & 42.000 & 41.000 & 97.674 & 95.349 \\
\hline 040 & 28.000 & 28.000 & 65.116 & 65.116 \\
\hline 41 & 26.000 & 26.000 & 60.465 & 60.465 \\
\hline 42 & 27.000 & 26.000 & 62.791 & 60.465 \\
\hline 4343 & 42.000 & 37.000 & 97.674 & 86.047 \\
\hline
\end{tabular}

Figure 5. Degree centrality of QQ human network. 


$\begin{array}{rrrrrr} & & & & & \\ & & & 1 & & \\ & & \text { OutDegree } & \text { InDegree } & \text { NrmOutDeg } & \text { NrmInDeg } \\ 1 & 1 & 22.000 & 27.000 & 51.163 & 62.791 \\ 2 & 2 & 19.000 & 25.000 & 44.186 & 58.140 \\ 3 & 3 & 23.000 & 24.000 & 53.488 & 55.814 \\ 4 & 4 & 15.000 & 18.000 & 34.884 & 41.860 \\ 5 & 5 & 14.000 & 13.000 & 32.558 & 30.233 \\ 6 & 6 & 19.000 & 18.000 & 44.186 & 41.860 \\ 7 & 7 & 6.000 & 8.000 & 13.953 & 18.605 \\ 8 & 8 & 18.000 & 20.000 & 41.860 & 46.512 \\ 9 & 9 & 20.000 & 17.000 & 46.512 & 39.535 \\ 10 & 10 & 24.000 & 21.000 & 55.814 & 48.837 \\ 11 & 11 & 17.000 & 20.000 & 39.535 & 46.512 \\ 12 & 12 & 25.000 & 23.000 & 58.140 & 53.488 \\ 13 & 13 & 20000 & 20.000 & 46.512 & 46.512 \\ 14 & 14 & 29.000 & 23.000 & 67.442 & 53.488 \\ 15 & 15 & 9.000 & 17.000 & 200.930 & 39.535 \\ 16 & 16 & 16.000 & 14.000 & 37.209 & 32.558 \\ 17 & 17 & 22.000 & 15.000 & 51.163 & 34.884 \\ 18 & 18 & 0.000 & 0.000 & 0.000 & 0.000 \\ 19 & 19 & 2.000 & 2.000 & 4.651 & 4.651 \\ 20 & 20 & 15.000 & 13.000 & 34.884 & 30.233 \\ 21 & 21 & 16.000 & 17.000 & 37.209 & 39.535 \\ 22 & 22 & 6.000 & 11.000 & 13.953 & 25.581 \\ 23 & 23 & 13.000 & 11.000 & 30.233 & 25.581 \\ 24 & 24 & 17.000 & 12.000 & 39.535 & 27.907 \\ 25 & 25 & 14.000 & 15.000 & 32.558 & 34.884 \\ 26 & 26 & 17.000 & 14.000 & 39.535 & 32.558 \\ 27 & 27 & 4.000 & 3.000 & 9.302 & 6.977 \\ 28 & 28 & 8.000 & 6.000 & 18.605 & 13.953 \\ 29 & 29 & 29.000 & 22.000 & 67.442 & 51.163 \\ 30 & 30 & 27.000 & 24.000 & 62.791 & 55.814 \\ 31 & 31 & 13.000 & 17.000 & 30.233 & 39.535 \\ 32 & 32 & 22.000 & 22.000 & 51.163 & 51.163 \\ 33 & 33 & 6.000 & 9.000 & 13.953 & 20.930 \\ 34 & 34 & 17.000 & 15.000 & 39.535 & 34.884 \\ 35 & 35 & 21.000 & 20.000 & 48.837 & 46.512 \\ 36 & 36 & 0.000 & 7.000 & 0.000 & 16.279 \\ 37 & 37 & 11.000 & 13.000 & 25.581 & 30.233 \\ 38 & 38 & 9.000 & 9.000 & 20.930 & 20.930 \\ 39 & 39 & 14.000 & 13.000 & 32.558 & 30.233 \\ 40 & 40 & 12.000 & 10.000 & 27.907 & 23.256 \\ 41 & 41 & 6.000 & 6.000 & 13.953 & 13.953 \\ 42 & 42 & 6.000 & 5.000 & 13.953 & 11.628 \\ 43 & 43 & 17.000 & 21.000 & 39.535 & 48.837 \\ & & & & & \end{array}$

Figure 6. Degree centrality of WeChat human network.

nodes. The nodes with higher node outdegree indicate that they should pay attention to other nodes. One node with higher node indegree and node outdegree menas that it is located in the center of the human network and they have more power and greate impacts on the small groups of information dissemination and exchanging [17]. As shown in Figure 5 \& Figure 6, the nodes with higher node indegree and outdegree of QQ human network are 1, 14, 15, 21, 26, and 31. These nodes are in the core position of the QQ human network. The nodes with higher node indegree of WeChat human network are 44, 1, 2, 3, 30, 14, and the nodes with higher node outdegree of WeChat human network are 44, 14, 30, 29, 12 , and 10 . So the nodes of 44,30 , and 14 are in the core position of the WeChat human network.

\subsubsection{Betweenness Centrality}

Betweenness centrality refers to the times of a node lying on the shortest path of any other two nodes [18]. Other nodes communicate with each other must depend on these nodes. The nodes with higher betweenness centrality mastering rich resources can control or distort the transmission of the netwok information. These nodes play a very important role in the exchange of information. The indicator can describe the degree of the nodes with higher betweenness centrality 
in the network controls other nodes in the process of information exchanging [15].

As shown in Figure 7 \& Figure 8, the nodes with higher betweenness centrality of QQ human network are 1,14,15, 21, 26, 31 and that of WeChat human network are 44,29,30. This means that other nodes of the human network are dependent on these core nodes in the process of communication [15] and these nodes can control the flow of information to a large extent.

The network centralization index of QQ is $0.28 \%$ and that of WeChat is $7.21 \%$. The lower value indicates that the most nodes in the network can get information without other nodes as an intermediary [17].

\subsubsection{Closeness Centrality}

Closeness centrality is different to the degree centrality and betweenness centrality. It refers to the extent of the node not controlled by other nodes. The smaller value illustrates that the node is in the core position of the human network, and it is not easily controlled by other nodes on the process of information dissemination [16]. Otherwise, the bigger value illustrates that the node is on the edge of the human network, and it is easier controlled by other nodes on the process of

$\begin{array}{rrrr} & & 1 & 2 \\ & & \text { Betweenness } & \text { nBetweenness } \\ 1 & 01 & 11.013 & 0.610 \\ 26 & 26 & 11.013 & 0.610 \\ 14 & 14 & 11.013 & 0.610 \\ 15 & 15 & 11.013 & 0.610 \\ 21 & 21 & 11.013 & 0.610 \\ 31 & 31 & 11.013 & 0.610 \\ 11 & 11 & 10.092 & 0.559 \\ 39 & 39 & 9.959 & 0.551 \\ 2 & 02 & 9.430 & 0.522 \\ 25 & 25 & 8.949 & 0.496 \\ 24 & 24 & 8.719 & 0.483 \\ 36 & 36 & 7.981 & 0.442 \\ 8 & 08 & 7.867 & 0.436 \\ 13 & 13 & 7.763 & 0.430 \\ 6 & 06 & 7.343 & 0.407 \\ 29 & 29 & 7.216 & 0.400 \\ 23 & 23 & 7.154 & 0.396 \\ 43 & 43 & 7.111 & 0.394 \\ 37 & 37 & 7.064 & 0.391 \\ 44 & 44 & 6.862 & 0.380 \\ 18 & 18 & 6.633 & 0.367 \\ 10 & 10 & 6.616 & 0.366 \\ 30 & 30 & 6.469 & 0.358 \\ 9 & 09 & 5.979 & 0.331 \\ 12 & 12 & 5.338 & 0.296 \\ 28 & 28 & 5.261 & 0.291 \\ 19 & 19 & 5.101 & 0.282 \\ 35 & 35 & 4.482 & 0.248 \\ 3 & 03 & 4.387 & 0.243 \\ 4 & 04 & 4.201 & 0.233 \\ 5 & 05 & 4.160 & 0.230 \\ 34 & 34 & 3.637 & 0.201 \\ 33 & 33 & 3.447 & 0.191 \\ 17 & 17 & 3.365 & 0.186 \\ 27 & 27 & 3.357 & 0.186 \\ 32 & 32 & 3.209 & 0.178 \\ 22 & 22 & 2.795 & 0.155 \\ 41 & 41 & 2.111 & 0.117 \\ 40 & 40 & 2.068 & 0.115 \\ 16 & 16 & 1.884 & 0.104 \\ 42 & 42 & 1.776 & 0.098 \\ 20 & 20 & 1.289 & 0.071 \\ 38 & 38 & 1.006 & 0.056 \\ 7 & 07 & 0.845 & 0.047 \\ 5 & & \end{array}$

Network Centralization Index $=0.28 \%$

Figure 7. Betweenness centrality of QQ. 


$\begin{array}{rrrr} & & 1 & 2 \\ & & \text { Betweenness } & \text { nBetweenness } \\ 44 & 44 & 153.429 & 8.496 \\ 29 & 29 & 104.885 & 5.808 \\ 30 & 30 & 69.357 & 3.840 \\ 26 & 26 & 62.423 & 3.456 \\ 1 & 1 & 57.853 & 3.203 \\ 14 & 14 & 47.231 & 2.615 \\ 10 & 10 & 45.589 & 2.524 \\ 17 & 17 & 45.534 & 2.521 \\ 12 & 12 & 43.843 & 2.428 \\ 43 & 43 & 41.897 & 2.320 \\ 8 & 8 & 41.272 & 2.285 \\ 13 & 13 & 40.683 & 2.253 \\ 24 & 24 & 31.968 & 1.770 \\ 32 & 32 & 30.023 & 1.662 \\ 35 & 35 & 29.736 & 1.646 \\ 3 & 3 & 27.363 & 1.515 \\ 2 & 2 & 24.558 & 1.360 \\ 4 & 4 & 21.995 & 1.218 \\ 9 & 9 & 21.959 & 1.216 \\ 34 & 34 & 19.755 & 1.094 \\ 11 & 11 & 18.502 & 1.024 \\ 25 & 25 & 16.700 & 0.925 \\ 21 & 21 & 15.789 & 0.874 \\ 37 & 37 & 15.771 & 0.873 \\ 23 & 23 & 15.192 & 0.841 \\ 16 & 16 & 14.201 & 0.786 \\ 6 & 6 & 14.124 & 0.782 \\ 31 & 31 & 14.041 & 0.777 \\ 40 & 40 & 13.962 & 0.773 \\ 39 & 39 & 12.965 & 0.718 \\ 15 & 15 & 11.947 & 0.662 \\ 38 & 38 & 6.789 & 0.376 \\ 5 & 5 & 4.815 & 0.267 \\ 20 & 20 & 4.321 & 0.239 \\ 22 & 22 & 3.179 & 0.176 \\ 42 & 42 & 1.575 & 0.087 \\ 41 & 41 & 1.452 & 0.080 \\ 33 & 33 & 1.127 & 0.062 \\ 27 & 27 & 0.735 & 0.041 \\ 7 & 7 & 0.584 & 0.032 \\ 28 & 28 & 0.572 & 0.032 \\ 19 & 19 & 0.305 & 0.017 \\ 36 & 36 & 0.000 & 0.000 \\ 18 & 18 & 0.000 & 0.000 \\ \text { Network } & & \\ & & & \end{array}$

Figure 8. Betweenness centrality of WeChat.

information dissemination [16].

From Figure 9 \& Figure 10, it shows that the nodes 1, 14, 15, 21, 26, 31 are not easier controlled by other nodes in QQ human network on the process of information dissemination and that in WeChat are the nodes 36, 44, 1, 2.These nodes are in the core position of the human network.

Degree centrality shows that the nodes 1, 14, 15, 21, 26 are in the absolute core position of QQ human network. Betweenness centrality shows that the ability of the five nodes controlling other nodes is strong and Closeness centrality shows that the five nodes are difficultly controlled by other nodes. The five nodes grasp the information dissemination and communication of the whole network. The network information can be accurately pushed through them.

Degree centrality shows that the nodes $44,30,14$ are in the absolute core position of WeChat human network. Betweenness centrality shows that the ability of the nodes 44,29, 30, controlling other nodes are strong and Closeness centrality shows that the nodes $36,44,1$, are difficultly be controlled by other nodes. The node 44 grasps the information dissemination and communication of the whole network. The network information can be accurately pushed through it. 


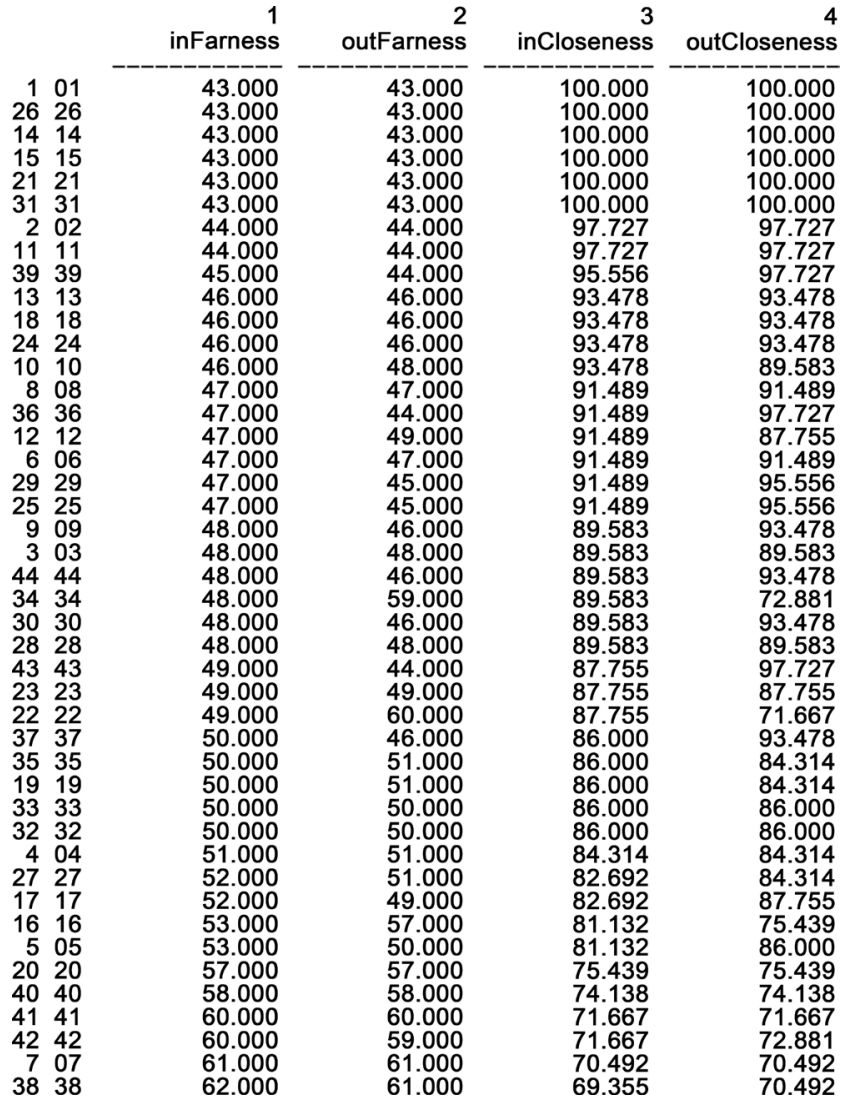

Figure 9. Closeness centrality of QQ.

\begin{tabular}{|c|c|c|c|c|}
\hline & inFarness & $\begin{array}{r}2 \\
\text { outFarness }\end{array}$ & $\begin{array}{r}3 \\
\text { inCloseness }\end{array}$ & $\begin{array}{r}4 \\
\text { outCloseness }\end{array}$ \\
\hline 3636 & 123.000 & 1892.000 & 34.959 & 2.273 \\
\hline $44 \quad 44$ & 138.000 & 96.000 & 31.159 & 44.792 \\
\hline 11 & 143.000 & 106.000 & 30.070 & 40.566 \\
\hline 2 & 145.000 & 109.000 & 29.655 & 39.450 \\
\hline 3 & 146.000 & 105.000 & 29.452 & 40.952 \\
\hline 3030 & 146.000 & 101.000 & 29.452 & 42.574 \\
\hline $\begin{array}{ll}14 & 14 \\
12 & 12\end{array}$ & 147.000 & 99.000 & 29.252 & 43.434 \\
\hline $\begin{array}{ll}12 & 12 \\
32 & 32\end{array}$ & 147.000 & 103.000 & 29.252 & 41.748 \\
\hline $\begin{array}{ll}32 & 32 \\
29 & 29\end{array}$ & $\begin{array}{l}148.000 \\
148.000\end{array}$ & $\begin{array}{r}106.000 \\
99.000\end{array}$ & $\begin{array}{r}29.054 \\
29054\end{array}$ & $\begin{array}{l}40.566 \\
43434\end{array}$ \\
\hline 1010 & 149.000 & 105.000 & 28.859 & 40.952 \\
\hline 88 & 150.000 & 111.000 & 28.667 & 38.739 \\
\hline 1111 & 150.000 & 112.000 & 28.667 & 38.393 \\
\hline 4343 & 150.000 & 111.000 & 28.667 & 38.739 \\
\hline 1313 & 151.000 & 109.000 & 28.477 & 39.450 \\
\hline 3535 & 151.000 & 107.000 & 28.477 & 40.187 \\
\hline 44 & 152.000 & 116.000 & 28.289 & 37.069 \\
\hline 2121 & 153.000 & 113.000 & 28.105 & 38.053 \\
\hline $\begin{array}{rr}31 & 31 \\
9 & 9\end{array}$ & 153.000 & 115.000 & 28.105 & $\begin{array}{l}37.391 \\
39815\end{array}$ \\
\hline 66 & 154.000 & 110.000 & $\begin{array}{l}28.105 \\
27.922\end{array}$ & 39.091 \\
\hline 1515 & 154.000 & 121.000 & 27.922 & 35.537 \\
\hline 3434 & 155.000 & 111.000 & 27.742 & 38.739 \\
\hline $\begin{array}{l}2626 \\
25\end{array}$ & 156.000 & 111.000 & 27.564 & 38.739 \\
\hline $\begin{array}{ll}5 & 25 \\
6 & 16\end{array}$ & $\begin{array}{l}156.000 \\
157.000\end{array}$ & $\begin{array}{l}116.000 \\
112.000\end{array}$ & $\begin{array}{r}27.564 \\
27.389\end{array}$ & $\begin{array}{l}37.069 \\
38.393\end{array}$ \\
\hline 17 & 157.000 & 106.000 & 27.389 & 40.566 \\
\hline 37 & 157.000 & 119.000 & 27.389 & 36.134 \\
\hline 2020 & 157.000 & 114.000 & 27.389 & 37.719 \\
\hline 5 & 158.000 & 115.000 & 27.215 & 37.391 \\
\hline $39 \quad 39$ & 159.000 & 114.000 & 27.044 & 37.719 \\
\hline 2424 & 159.000 & 111.000 & 27.044 & 38.739 \\
\hline 4040 & 160.000 & 116.000 & 26.875 & 37.069 \\
\hline 2222 & 160.000 & 125.000 & 26.875 & 34.400 \\
\hline $\begin{array}{ll}23 & 23 \\
33 & 33\end{array}$ & 162.000 & 115.000 & 26.543 & 37.391 \\
\hline $\begin{array}{ll}3 & 33 \\
8 & 38\end{array}$ & $\begin{array}{l}162.000 \\
163.000\end{array}$ & $\begin{array}{l}125.000 \\
121.000\end{array}$ & $\begin{array}{l}26.543 \\
26.380\end{array}$ & $\begin{array}{l}34.400 \\
35.537\end{array}$ \\
\hline 77 & 165.000 & 131.000 & $\begin{array}{l}20.000 \\
26.061\end{array}$ & 32.824 \\
\hline 2828 & 166.000 & 121.000 & 25.904 & 35.537 \\
\hline 4242 & 167.000 & 123.000 & 25.749 & 34.959 \\
\hline 7) & 168.000 & 127.000 & 25.595 & 33.858 \\
\hline $\begin{array}{ll}27 & 27 \\
19 & 19\end{array}$ & $\begin{array}{l}176.000 \\
183.000\end{array}$ & $\begin{array}{l}129.000 \\
138.000\end{array}$ & $\begin{array}{l}24.432 \\
23.497\end{array}$ & $\begin{array}{l}33.333 \\
31.159\end{array}$ \\
\hline & & & & \\
\hline
\end{tabular}

Figure 10. Closeness centrality of WeChat. 
Table 5. The three Centralities of QQ Human Network (Top 6).

\begin{tabular}{ccc}
\hline Degree Centrality & Betweenness Centrality & Closeness Centrality \\
\hline 1 & 1 & 1 \\
14 & 14 & 14 \\
15 & 15 & 15 \\
21 & 21 & 21 \\
26 & 26 & 26 \\
31 & 31 & 31 \\
\hline
\end{tabular}

Table 6. The three Centralities of WeChat Human Network (Top 3).

\begin{tabular}{ccc}
\hline Degree Centrality & Betweenness Centrality & Closeness Centrality \\
\hline 44 & 44 & 36 \\
30 & 29 & 44 \\
14 & 30 & 1 \\
\hline
\end{tabular}

\subsection{Block Model Analysis Based on CONCOR}

Block model method can partition each point based on structural information and simplify the information. Block model method can classify the nodes using structural equivalence [19]. The function "Network-Role-Structure-CONCOR" in the Ucinet can calculate the number of subgroups in the "buddy relationship". The results are shown below.

From Figure 11 \& Figure 12, the QQ human network is devided into 7 "buddy relationship" subgroups, and the WeChat is divided into 5. The tree diagram can express the members of each subgroup and their internal network structure. Each subgroup constitutes a small group and the inner members of the group are closely linked. There is no association between groups. By excavating the common concerning information of each group, it can push the accurate information and share the information frequently, which can also improve the accuracy and efficiency of the information pushing.

\section{Results}

\subsection{Analysis of the Whole Human Network}

By constructing the human network sociogram, it can get the high impact nodes of the human network, which can be the opinion leaders because of the great ability to acquire the information resource. By analyzing the network density it can conclude that the members of QQ human network are communicating closely. The frequency of interaction among members of the network is high, which facilitates the dissemination and sharing the knowledge among members. But the WeChat is less tightly linked. Through analyzing the human network accessibility, it shows that the two human networks have a small world phenomenon, and the network has strong internal cohesion. By analyzing the network and its internal member nodes, it can push the precise information and improve 


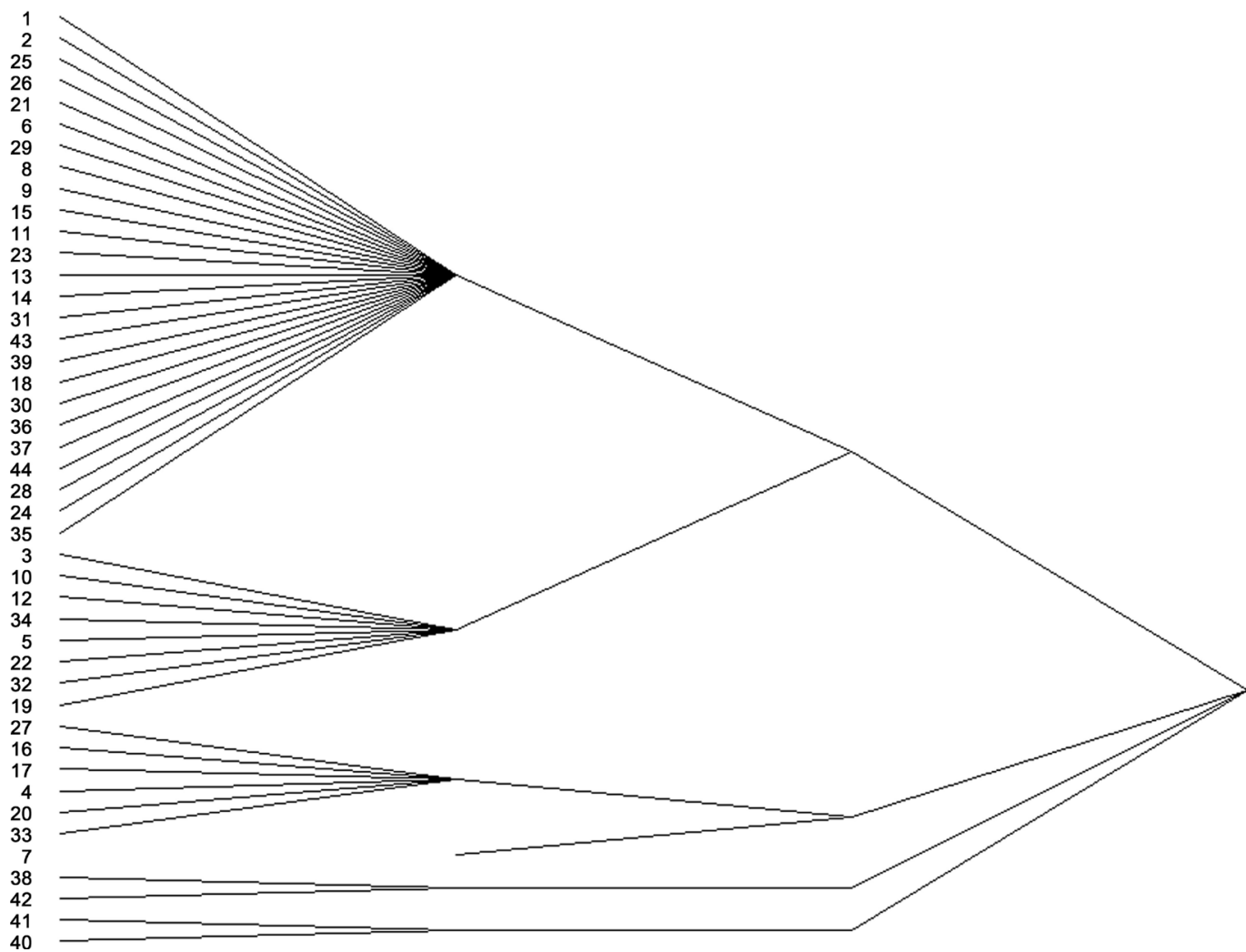

Figure 11. Block model analysis of QQ.

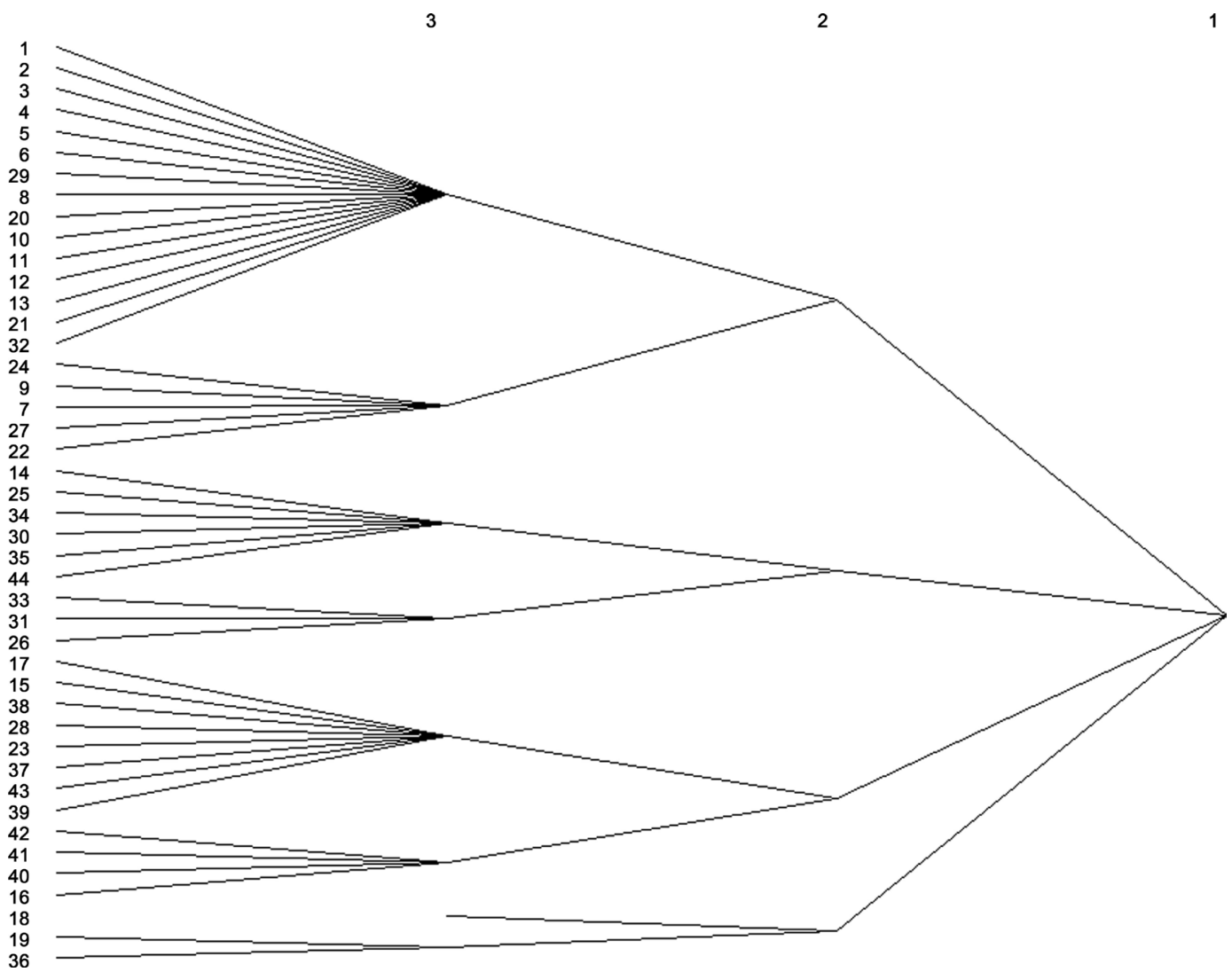

Figure 12. Block model analysis of WeChat. 
the frequency of interaction among network members.

\subsection{Analysis of Human Network Centricity}

Analyzing the degree centrality can get the central nodes of the human network, which have great power in the process of information transmission and great influence on the communication between the members of the human network [17]. The betweenness centrality can get the nodes located in many communication networks. This kind of nodes can describe the degree of controlling other members during the process of information exchanging [15]. Analyzing the closeness centrality can get the nodes which not easily controlled by other nodes of human network [16].

By analyzing the nodes $1,14,15,21,26,31$ of QQ human network and the node 44 of WeChat, it can find that these nodes occupy the most important position in the entire interpersonal network and master the trends of information dissemination and communication. It can improve the accuracy of information transmission of the whole network.

\subsection{Analysis of Block Model}

The analysis of block model can caculate the number of interpersonal subgroups and the closeness degree within the group members. Mining the common concerned information of each group can improve the accuracy and efficiency of information pushing.

\section{Conclusion}

This paper analyzes the whole human network, human network centricity and block model of the QQ human network and WeChat human network. It analyzes the characteristics of the human network from multiple measurement dimensions. By analyzing the whole human network, it can obtain the higher impact nodes, opinion leaders and it finds that the two human networks emerge the small word phenomenon. These nodes can push the precise information and improve the frequency of interaction among network members. By analyzing the human network centricity, it obtains the central nodes. These nodes occupy the most important position in the entire interpersonal network. They master the trends of information dissemination and communication. They can improve the accuracy of information transmission of the whole network. By analyzing the block model, it can obtain the subgroups of human network and the closeness degree within the group members. It can improve the efficiency of information pushing, and frequency of information sharing through each subgroup. We hope to provide a new direction for the research of human network precise information pushing.

\section{Acknowledgements}

This paper is supported by the National Social Science Foundation of China (Grant No. 14CTQ022). 


\section{References}

[1] Borgatti, S.P.E., Everett, M.G. and Johnson, J.C. (2013) Analyzing Social Networks. Sage, London.

[2] Pan, S. (2008) The Construction of the Human Network Research Pattern Based on Quantitative Analysis Method. Journal of Information, 28, 115-117.

http://dx.chinadoi.cn/10.3969/j.issn.1002-1965.2008.02.011

[3] Bao, C., Xie, X. and Shen, K.N. (2003) Social Network Analysis: Application in Competitive Intelligence. Journal of the China Society for Scientific and Technical Informaion, 22, 365-374. http://dx.chinadoi.cn/10.3969/j.issn.1000-0135.2003.03.021

[4] Wang, Z., Wang, W. and Jin, X. (2010) Construction of Competitive Intelligence Social Network Relationship Model \& Its Implementation. Information Studies: Theory \& Application, 33, 5-10.

[5] Wu, X., Lv, J. and Li, D. (2009) Network Human Competitive Intelligence Analysis Based on Hyperlink. Journal of Information, 28, 99-102. http://dx.chinadoi.cn/10.3969/j.issn.1002-1965.2009.05.023

[6] Isba, R., Woolf, K. and Hanneman, R. (2017) Social Network Analysis in Medical Education. Medical Education, 51, 81-87. https://doi.org/10.1111/medu.13152

[7] Colladon, A. and Remondi, E. (2017) Using Social Network Analysis to Prevent Money Laundering. Expert Systems with Applications, 67, 49-58. https://doi.org/10.1016/j.eswa.2016.09.029

[8] Chan, W. and Hsu, C. (2010) How Hyper-Network Analysis Helps Understand Human Networks? Service Science, 2, 270-280. https://doi.org/10.1287/serv.2.4.270

[9] Du, N., Wang, B. and Wu, B. (2008) Community Detection in Complex Networks. Journal of Computer Science and Technology, 23, 672-683. http://d.scholar.cnki.net/link/doi/SSJD_U/SSJD00003317334 https://doi.org/10.1007/s11390-008-9163-6

[10] Herman, I., Melançon, G. and Marshall, M.S. (2000) Graph Visualization and Navigation in Information Visualization: A Survey. IEEE Transactions on Visualization \& Computer Graphics, 6, 24-43. https://doi.org/10.1109/2945.841119 http://doi.ieeecomputersociety.org/10.1109/2945.841119

[11] Liu, J. (2004) Social Network Analysis Introduction. Social Sciences Academic Press, Beijing, 9-14.

[12] Borgatti, S., Everett, M.G. and Freeman, L.C. (2002) UCINET VI for Windows: Software for Social Network Analysis.

[13] Wang, L. (2009) Typical Software Tools and Methods for Social Network Analysis. China Educational Technology, 4, 95-100. http://dx.chinadoi.cn/10.3969/j.issn.1006-9860.2009.04.026

[14] He, K. and Xu, P. (2012) Research on IRC Network between Organizations by SNA: The Case of the First 32 IRCs in China. Journal of Information, 31, 202-206. http://dx.chinadoi.cn/10.3969/j.issn.1002-1965.2012.04.040

[15] Ge, Y. (2012) Research on Communication Characteristics in Microblog of Agriculture Based on Social Network Analysis-Taking "Agricultural Industry" Community in SINA for Example. Nanjing Agricultural University, Nanjing. http://dx.chinadoi.cn/10.7666/d.Y2360163

[16] Lei, H. and Jia, Y. (2013) Analysis on Characteristices of Social Network Structure of IT Micro-Blog. Technology Economics, 32, 9-13. http://dx.chinadoi.cn/10.3969/j.issn.1002-980X.2013.11.002

[17] Liang, P. and Zong, L. (2010) Research on Microblog Information Dissemination 
Based on SNA Centrality Analysis-A Case Study with Sina Microblog. Documentation, Information \& Knowledge, 6, 92-97.

http://dx.chinadoi.cn/10.13366/j.dik.2010.06.004

[18] Freeman, L.C. (1977) A Set of Measures of Centrality Based on Betweenness. Sociometry, 40, 35-41. https://doi.org/10.2307/3033543

[19] Liu, J. (2006) A Holistic Network Approach to the Study of the Social Support Network in Village Fa-The Block model and Its Application. Society, 26, 69-80.

https://doi.org/10.3969/j.issn.1004-8804.2006.03.004

Submit or recommend next manuscript to SCIRP and we will provide best service for you:

Accepting pre-submission inquiries through Email, Facebook, LinkedIn, Twitter, etc. A wide selection of journals (inclusive of 9 subjects, more than 200 journals)

Providing 24-hour high-quality service

User-friendly online submission system

Fair and swift peer-review system

Efficient typesetting and proofreading procedure

Display of the result of downloads and visits, as well as the number of cited articles

Maximum dissemination of your research work

Submit your manuscript at: http://papersubmission.scirp.org/

Or contact sn@scirp.org 